\title{
DESIGN AND FABRICATION OF A SMALL SCALE COCOPEAT COMPACTION MACHINE
}

\author{
Evans Magara \\ Faculty of Engineering
Technology, \\ Multimedia University, \\ Kenya \\ P. O. Box 15653-00503, \\ Mbagathi, Nairobi. \\ Abel Mayaka \\ Faculty of Engineeri
Technology, \\ Multimedia University, \\ Kenya \\ P. O. Box 15653-00503, \\ Mbagathi, Nairobi.
}

\begin{abstract}
Coconut is one of the major crops grown by small-scale farmers in Kenya coast. This crop has a great potential to contribute to the economy of the region, owing to the wide applications of its products. Virtually all parts of the crop including its leaves, fruit, stem and roots are useful for many products, such as food, beverages, cosmetics, medicine, furniture, textiles and cocopeat. Cocopeat is a by-product in fibre production from coconut husks. The cocopeat is used as a planting medium in soilless culture in agricultural production and as a soil substitute in containerized crop production. Recently, these soilless media have received much interest especially in commercial applications in Kenya, especially in horticultural farms. Since the cocopeat is a loose material, its transportation poses a challenge due to its bulkiness. Therefore a need for compacting it for ease of transportation. For this purpose, an automated cocopeat block making machine was developed to compact the loose cocopeat into uniform blocks to facilitate stacking and ease of transportation from source to agricultural farms across the country. The machine was automated.
\end{abstract}

Key words: Cocopeat, design, fabrication, Density, Compaction.

\section{INTRODUCTION}

In the coastal counties of Kenya, many small scale farmers rely on the coconut crop for their livelihood. Kenya has 436,634 acres of land under coconut cultivation with a tree population of 9.9 million producing over 246 million mature nuts annually (Agriculture and Food Authority, 2019).The estimated potential of the coconut industry stands at KES 25 billion annually with the current exploited monetary value at KES 12.2 billion which is only $48.8 \%$ of the estimated potential. This is attributed to the underdeveloped coconut value chain in Kenya.

According to the Economic survey report of 2019 (Kenya Bureau of Statistics , 2019). Kenya produced 107,000 metric tons of coconut and imported 1,000 metric tons of coconut, this made a domestic supply of 108 metric tons in 2018. All this was used for domestic consumption as food, none was processed, used as feed or seed for replanting.

In 2017, Kenya produced 124,000 metric tons of coconuts of which 10,000 metric tons were used as feed, 34,000 metric tons processed, and 72,000 metric tons as

\author{
Charles Ondieki \\ Faculty of Engineering and \\ Technology, \\ Multimedia University, \\ Kenya \\ P. O. Box 15653-00503, \\ Mbagathi, Nairobi.
}

\author{
Bernard Ikua \\ School of Mechanical \\ Engineering, JKUAT, \\ Kenya \\ P.O. Box 62000-00100 \\ Nairobi, Kenya
}

food while 8,000 metric tons went to waste. The Kenya Government estimates that the coconut sub-sector can contribute 4.5 percent of the Agricultural Gross Domestic Product (GDP) and 1.2 per cent of the national GDP at its full potential according to the Economic Survey Report of 2018 (Kenya National Bureau of Statistics, 2018). Despite the high coconut production rates, the sector is faced with many challenges that have made it not to realize its full potential. These challenges include: excessive harvesting of old coconut orchards, lack of proper storage facilities for harvested coconuts, lack of technologies for mass production, lack of machines in the coconut value chain to assist in coconut processing, lack of trained personnel to operate the processing machines, declining markets for traditional coconut products, limited research on ways to improve the coconut value chain and the exploitation of coconut farmers by middlemen in the value chain. These challenges have led to the development of coconut processing machines in the country, their design, manufacture, fabrication and performance evaluation, to realize maximum benefits in both products and by-products in the coconut value chain to improve the income levels of farmers in coconut growing areas in Kenya.

The demand for coconut products over time has decreased and this has necessitated the need to look for other profitable markets for the products. This requires stakeholders to bring the existing coconut industry to higher level in the development of the coconut value chain possibly by adding value. One way to do this is to use technology in the extraction of fiber (Krishnamurthy, Maheswari, Udayarani, \& Gowtham, 2009). In the extraction of fiber, cocopeat is produced as a by-product. Cocopeat is used in agriculture as a growing medium for high value crops and in the propagation of seedlings, as it has conducive properties for growth and propagation (Fernando \& Amarasinghe, 2017).

Cocopeat as a growing medium is becoming popular worldwide. It serves as a substrate for hydroponics and growing mixes in agriculture (Shiva, Anandkumar, \& Naorem, 2017). For ease of transportation to the agricultural sites, the bulky cocopeat needs to be compacted or densified. Compaction technologies, classified as highpressure compaction, medium pressure compaction and low-pressure compaction with binder are used in compaction. Currently the compaction and densification technologies include the screw and ram, and the piston 
compaction. Ram and piston presses and screw extrusion presses are used for compaction in high- pressure compaction. The compacted products in this case are completely solid, the screw press compacted blocks have a concentric hole giving them better compaction characteristics due to the larger specific area created (7).

Compaction is the pressing of particles together in a confined volume. The fine materials, which deform under high pressures, need no binders when pressed. Valence forces, interlocking forces or the van der Waals forces influence the compaction characteristics of the blocks. The prevailing high-pressure forces act on the natural components of the compressed material to become binders although some material still may need binders even under high pressures conditions (Lardinois \& Klundert, 1993).

Compaction makes transportation of cocopeat easier, and thus, the development of cocopeat compaction machines is essential for the agricultural sector. The compacted blocks must have the right compaction characteristics to avoid breakages during transportation. Press pressure and cocopeat moisture content are critical for the achievement of the the required characteristics (Agriculture and Food Authority, 2016).

The purpose of this research is to develop a simple and efficient cocopeat compaction machine for use by small scale coconut farmers.

\subsection{Problem statement.}

The coconut sub-sector demonstrate an immense potential to drive the economic development in the coconut growing areas. This potential is far from exploited as only $48 \%$ of the estimated potential is exploited (Khurmi R \& Gupta, 2005). This high potential of the coconut sector in Kenya necessitated a re-look at the coconut value chain to realize its full utilization. In the coconut value chain, cocopeat transportation to agricultural firms is difficult due to its bulky and spongy nature therefore the need to compact it into blocks of optimum density for ease of transportation. The cocopeat compaction machines available for this purpose and in small-scale use in the country are manual with no data relating to their maintenance, operation and performance. On the other hand, the machines in industrial use are powered, automated, and efficient and have high production rates (Zion, Rackielyn, \& Mirafel, 2019). These automated machines are expensive for small-scale use in terms of purchase, maintenance and operation. Thus, the need to develop a low cost locally- fabricated and automated cocopeat compaction machine that is efficient, accessible and easy to operate for small-scale use in the country.

\subsection{RESEARCH OBJECTIVES}

1) To carry out analysis of cocopeat compaction machines.

2) To design a machine for compacting cocopeat.

3) To fabricate a machine for compacting cocopeat.

\subsection{RESEARCH MATERIALS AND METHODS}

The research material used was cocopeat from cocogrow Ltd. Developmental research design was used. Analysis of

existing compacting machines was done, then design of the compacting machine which followed the following guidelines, preliminary research, machine design considerations, design concept development, compaction machine fabrication and automation and testing. The machine design considerations were, cost of machine developed, size of the blocks produced, strength and availability of the materials used, rigidity of the system, operation and safety considerations. The equipment used are the universal drilling machine, lathe machine, welding machine, power saw, hammer, and digital electronic balance, pressure gauge, moisture sensor and hand gloves. These equipment were at Mechanical laboratory at multimedia University of Kenya where the design, fabrication and testing was done.

\subsection{Analysis of Cocopeat Compaction Machines}

The cocopeat block making machines in the market are categorized as manual and automatic machine. An analysis was carried out on cocopeat compaction machines and the results tabulated as below.

Table 1: Analysis of Cocopeat Compaction Machines

\begin{tabular}{|c|c|c|}
\hline $\begin{array}{l}\text { Manual } \\
\text { machine }\end{array}$ & $\begin{array}{l}\text { Semi-automatic } \\
\text { machine }\end{array}$ & Automated machine \\
\hline $\begin{array}{l}\text { Do not use } \\
\text { any form of } \\
\text { hydraulic } \\
\text { system } \\
\end{array}$ & $\begin{array}{ll}\text { Use } & \text { hydraulic } \\
\text { system } & \end{array}$ & Use hydraulic system \\
\hline \begin{tabular}{|l|l} 
Do not use \\
electricity
\end{tabular} & Use electricity & Use electricity \\
\hline $\begin{array}{l}\text { Have } \\
\text { significantly } \\
\text { low } \\
\text { maintenance } \\
\text { costs } \\
\end{array}$ & $\begin{array}{l}\text { Moderate } \\
\text { maintenance cost }\end{array}$ & High maintenance cost \\
\hline \begin{tabular}{|l} 
Require \\
minimal \\
skills \\
operate
\end{tabular} & \begin{tabular}{|lr} 
Some & operations \\
require & skilled \\
labour & \\
\end{tabular} & $\begin{array}{l}\text { Require high skilled } \\
\text { labour to operate }\end{array}$ \\
\hline $\begin{array}{l}\text { All } \\
\text { operations } \\
\text { are by hand } \\
\end{array}$ & $\begin{array}{l}\text { Some operations are } \\
\text { by hand }\end{array}$ & $\begin{array}{l}\text { All operations are } \\
\text { automated }\end{array}$ \\
\hline $\begin{array}{l}\text { Are cheaper } \\
\text { compared to } \\
\text { automated } \\
\text { machines } \\
\end{array}$ & $\begin{array}{ll}\text { Relatively } & \text { cheaper } \\
\text { that } & \text { automated } \\
\text { machines } & \end{array}$ & $\begin{array}{ll}\text { Are } & \text { expensive } \\
\text { compared to manual } \\
\text { machines }\end{array}$ \\
\hline $\begin{array}{lr}\text { Are simple in } \\
\text { design } & \text { and } \\
\text { suitable } & \text { for } \\
\text { small } & \text { scale } \\
\text { use } & \\
\end{array}$ & $\begin{array}{l}\text { Are } r \text { somehow } \\
\text { complex in design } \\
\text { and used for medium } \\
\text { usage }\end{array}$ & $\begin{array}{l}\text { Complex in design and } \\
\text { suitable for large } \\
\text { industrial use }\end{array}$ \\
\hline $\begin{array}{l}\text { Have low } \\
\text { production } \\
\text { rates } \\
\end{array}$ & $\begin{array}{l}\text { Medium production } \\
\text { rates }\end{array}$ & High production rates \\
\hline $\begin{array}{l}\text { Operators } \\
\text { become } \\
\text { fatigued } \\
\text { quickly for } \\
\text { continuous } \\
\text { operations } \\
\end{array}$ & $\begin{array}{l}\text { Operators become } \\
\text { fatigued over time }\end{array}$ & $\begin{array}{l}\text { Operators are not } \\
\text { fatigued } \\
\text { continuous }\end{array}$ \\
\hline $\begin{array}{l}\text { Non uniform } \\
\text { blocks are }\end{array}$ & $\begin{array}{l}\text { Uniform blocks are } \\
\text { produced }\end{array}$ & $\begin{array}{l}\text { Uniform } \\
\text { produced }\end{array}$ \\
\hline
\end{tabular}


International Journal of Engineering Applied Sciences and Technology, 2021

Vol. 6, Issue 5, ISSN No. 2455-2143, Pages 47-60

Published Online September 2021 in IJEAST (http://www.ijeast.com)

\begin{tabular}{|c|c|c|}
\hline produced & & \\
\hline Inefficient & Relatively efficient & Efficient \\
\hline $\begin{array}{l}\text { Manually } \\
\text { operated }\end{array}$ & Semi-automatic & Automatic \\
\hline \begin{tabular}{|l} 
Low \\
productivity \\
$(20 \quad$ blocks \\
per hour \\
\end{tabular} & $\begin{array}{l}\text { Medium productivity } \\
\text { (100 blocks per hour }\end{array}$ & $\begin{array}{l}\text { High productivity } 300 \\
\text { blocks per hour }\end{array}$ \\
\hline $\begin{array}{l}\text { Brick size (L } \\
x \text { W X H); } \\
\text { Not uniform }\end{array}$ & $\begin{array}{l}\text { Brick size (L x W x } \\
\mathrm{H}) ; 30 \times 30 \times 10 \mathrm{~cm} \text {, } \\
\text { uniform }\end{array}$ & $\begin{array}{l}\text { Brick size }(\mathrm{L} \times \mathrm{W} \times \mathrm{H} \\
30 \mathrm{~cm} \times 30 \mathrm{~cm} \times 10 \mathrm{~cm}\end{array}$ \\
\hline $\begin{array}{l}\text { Compaction } \\
\text { ration, not } \\
\text { uniform }\end{array}$ & Compaction ratio 5:1 & $\begin{array}{l}\text { Compaction ration , } \\
6: 1\end{array}$ \\
\hline $\begin{array}{ll}\text { Cost } & \text { Ksh. } \\
90,000 & \end{array}$ & \begin{tabular}{|ll} 
Cost & Ksh. \\
$3,063,554.02$ & \\
\end{tabular} & $\begin{array}{ll}\text { Cost } & \text { Ksh. } \\
10,421,990.00 & \end{array}$ \\
\hline
\end{tabular}

\begin{tabular}{|l|l|}
\hline Yields strength $\sigma_{\mathrm{y}}$ shear & $145 \mathrm{Mpa}$ \\
\hline Modulus of elasticity $(\mathrm{E})$ & $200 \mathrm{Gpa}$ \\
\hline Modulus of rigidity & $77.2 \mathrm{Gpa}$ \\
\hline Density (r) & $7860 \mathrm{Kg} / \mathrm{m}^{2}$ \\
\hline $\begin{array}{l}\text { Coefficient of thermal } \\
\text { expansion }\end{array}$ & $11.7 \mathrm{Gpa}$ \\
\hline
\end{tabular}

\section{Determination of Yields stress}

Maximum allowable stress = yield stress point/ Factor of safety

\subsection{Design of Machine components}

\section{Frame}

The frame is the housing of the machine. It is divided into the front and rear section. The front section houses the mold and the compactor, has guides for the mold and compactor and it

\section{DESIGN OF AUTOMATED COCOPEAT} COMPACTION MACHINE

The conceptual design of the compacting machine developed was as shown in plate 1 . The conceptual design was based on the usage and purpose of the blocks, the composition of the blocks and mode of transportation.


also has the compacting plate while the rear side has the mixing chamber, motor and the pulley.



Plate 3: Frame

Plate 1: Conceptual design of the machine developed Author)

2.1 Design Concepts

The following concept was developed

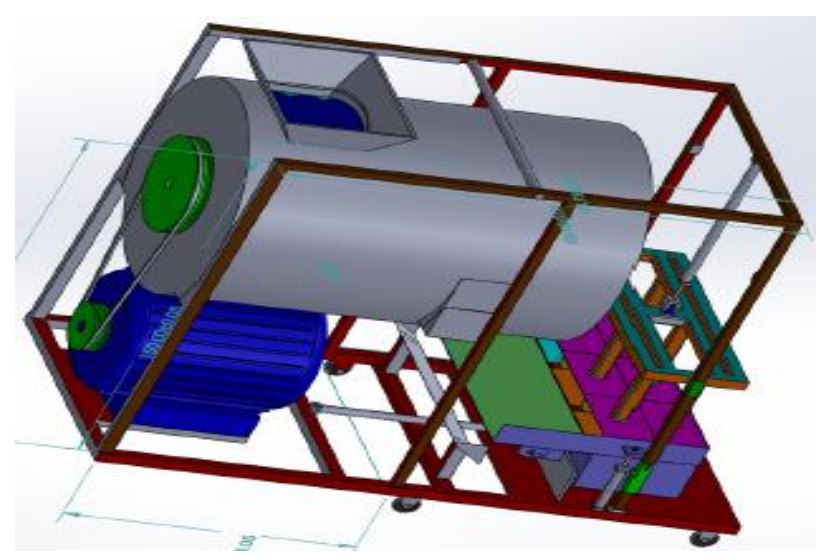

Plate 2: Design Concepts ( Author)

\subsection{Design calculations}

The design calculations were as follows.

The material properties

The material used was mild steel with the following properties

\begin{tabular}{|l|c|}
\hline Ultimate tensile strength & $400 \mathrm{Mpa}$ \\
\hline Yield strength $\sigma_{\mathrm{y}}$ tension & $250 \mathrm{Mpa}$ \\
\hline
\end{tabular}

\subsection{The mould chamber}

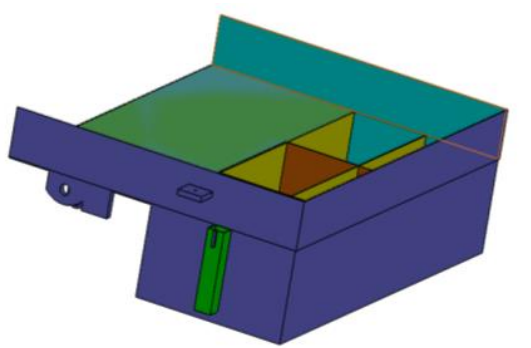

Plate 41: Mould developed

The mould chamber as in plate 3-4 was determined based on the size of the cocopeat block to be produced and the amount of the cocopeat mixture needed to produce the block, a constant volume approach was used. This was preferred as it produces blocks of the same dimensions for ease of stacking and transportation. The mould chamber was $600 \mathrm{~mm}$ by $300 \mathrm{~mm}$ by $80 \mathrm{~mm}$

The factors that were considered include

- The cocopeat block dimensions ( $\mathrm{L} \times \mathrm{W} \times \mathrm{H})$.(1)

- $\quad$ Factor of safety $=4$

- The mould chamber to produce 4 blocks in a cycle

- Mould chamber dimensions

- Block Cross -Sectional area

- Design compaction pressure

- Design pressure

\subsection{Mould Plate Thickness}


The mould plate thickness was calculated using the relation,

(Equating the maximum bending moment with the bending resistance of the plate material)

$\mathrm{Wl}^{2} / 8=\mathrm{f} \times \mathrm{Z}$,

Where

$\mathrm{W}=$ load

$1=$ length

$\mathrm{t}=$ thickness of plate

$\mathrm{F}=$ allowable bending stress $=0.66 \sigma \mathrm{y}$

$\mathrm{Z}=$ section modulus

$$
\mathrm{Z}=\frac{b t^{2}}{6}
$$

From the calculations thickness of the mould chamber walls was $10.8 \mathrm{~mm}$

\subsection{Deflection of the mould}

The maximum deflection is given by $y_{\max }=\frac{5 w l^{4}}{384 E I}$

Where :

$\mathrm{W}=$ distributed $\operatorname{load}(\mathrm{N} / \mathrm{m})$

$\mathrm{L} \quad=$ Length of applied load $(\mathrm{m})$

$\mathrm{I}=$ area moment of inertia $\left(\mathrm{m}^{4}\right)$

$\mathrm{E}=$ Young's Modulus of elasticity $\left(\mathrm{Pa}\right.$ or $\left.\mathrm{N} / \mathrm{m}^{2}\right)$

$\mathrm{y}_{\max }=$ Maximum deflection

Deflection, $\mathrm{y}_{\max }=\frac{5 w l^{4}}{384 E I}$

This was considered minimal and therefore, the blocks had straight edges. The partitions in the mold chamber were joined by arc welding.

\subsection{The piston rods}

Since the load carrying capacity of the rods depend on the condition on the restraint at the two end of the rod, as shown in figure 3-2, which is given by a dimensionless quantity called end fixity coefficient(n) whose values are given in plate $3-6$,

\begin{tabular}{|c|c|c|}
\hline S. No & End conditions & Bnd fuxity coefficient (C) \\
\hline 1. & Both ends hinged & 1 \\
\hline 2. & Bothends fixed & 4 \\
\hline 3. & One end fixed and other hinged & 2 \\
\hline 4. & One end fixed and other end free & 0.25 \\
\hline
\end{tabular}

Plate 5: Values of end fixity coefficient (C) for various end conditions

Using the Euler's equation, force per $\operatorname{rod} \mathrm{F}_{\mathrm{cr}}=\frac{C \pi^{2} E I}{L^{2}}$,

Where

$E=$ modulus of elasticity or young's modulus for the material

$A=$ area of cross section

$L=$ length of the beam

$C=$ constant representing the end conditions of the piston

or end fixity

$I=$ moment of area

$\mathrm{F}_{\mathrm{cr}}=$ force per rod (4 number)
Considering a circular rod, $I=\frac{\pi r^{4}}{4}, F_{c r}=\frac{\pi^{2} E\left(\pi r^{4}\right)}{4 L^{2}}$, $r^{4} \geq \frac{4 L^{2} F C r}{\pi^{3} E}$

The diameter of the piston rods is $100 \mathrm{~mm}$

2.8 Mixing cylinder design

The mixing cylinder is where a rotating shaft joined to mixing screw carries out the mixing process.

\section{Determination of mixing cylinder volume}

The mixing cylinder was designed to accommodate the volume of mix needed to produce at least 20 blocks per run. The length of the mixing chamber $=1.0 \mathrm{~m}$, therefore, the diameter of the mixing chamber was given by

$\mathrm{V}=\pi r^{2} l$

The dimensions of the mixing chamber were $1 \mathrm{~m}$ length and $0.66 \mathrm{~m}$ diameter.

\subsection{Bolt sizes}

Since the machine was required to have ease of movement form one station to another, the major parts were fastened using bolts and nuts.

The bolt diameter was given by

$P=\frac{1}{4} \pi d_{c}^{2} * \sigma_{c}$

Where P- load

$\mathrm{d}=$ nominal diameter

$\mathrm{d}_{\mathrm{c}}=$ core diameter

$\sigma_{c}=$ allowable tensile stress

\section{Mixing force of the mixer}

The mixing force was calculated as below

$F=M_{p} x g$

$\mathrm{F}=$ force

$\mathrm{M}=$ mass of cocopeat $\mathrm{g}=$ gravitational acceleration

Loose density of cocopeat is $20 \mathrm{~kg} / \mathrm{m}^{3}$

Mass $=$ density $\mathrm{x}$ volume

Hopper

The hopper outlet must be large enough to prevent cohesive arches or stable ratholes from developing. The outlet size therefore depends on the cohesive strength and the bulk density of the cocopeat dust. The hopper was made of mild steel to standard at an inclined angle of $60^{\circ}$ with respect to the mixing chamber when fixed horizontal.

\subsection{Shaft}

For the mixer, a shaft was used to support the rotating mixing blades. The shaft was subjected to axial or transverse loads as well as torsional loads acting singly or in combination. The shaft carries the blades and is powered by an electric motor though bearings and pulley system. The forces acting on the blades are transmitted to the shaft. These forces include the reaction due to weight of the blades, green compression strength of the mixer cocopeat and centrifugal effect of both the shaft and the blades.

\subsection{Mixing speed}

The shaft is attached to a pulley on the pulley system

Using pulley ratio and given that the motor speed $N_{1}$ is $1450 \mathrm{rpm}$, the shaft speed, $\mathrm{N}_{2}$ in rpm was determined from the expression: 


$$
\frac{N_{1}}{N_{2}}=\frac{D 2}{D 1}
$$

Angular velocity of the shaft $=\omega_{s}=\frac{2 \pi N_{2}}{60}=26.18$ rad.....

\section{Torque on the shaft}

Torque of the shaft,$T_{S}=r_{b} X F_{s} \ldots$.

$T_{S}=$ torque of the shaft

$r_{b}=$ radius of the blades $=(0.33 \mathrm{~m})$

$F_{s}=$ force acting on the shaft

Power required for mixing the cocopeat

$P_{s}(W)=T_{S}(N . m) X \omega_{s}$

The minimum diameter of the shaft

$d_{S}=\sqrt[s]{\frac{16 T_{S}}{\pi S_{S}}}$

\section{The efficiency of the mixer}

The efficiency of the mixer was calculated using the equation $\varepsilon=\frac{\text { output power/ powere required }}{\text { input power / power supplied }} \times 100$

Where, The power required was calculated as $732.18 \mathrm{~W}$,

The power supplied was the rating of the electric motor provided is $0.75 \mathrm{Kw}$, and

The efficiency was evaluated as $97 \%$

\section{Determined parameters}

\begin{tabular}{|l|l|}
\hline Parameter & Determined parameter \\
\hline Yield stress & $62.5 \mathrm{Mpa}$ \\
\hline Mold thickness & $10.8 \mathrm{~mm}$ \\
\hline Mold deflection & $0.000104 \mathrm{~mm}$ \\
\hline Piston rods diameter & $100 \mathrm{~mm}$ \\
\hline $\begin{array}{l}\text { Length of mixing } \\
\text { chamber }\end{array}$ & $1 \mathrm{~m}$ \\
\hline $\begin{array}{l}\text { Diameter of mixing } \\
\text { chamber }\end{array}$ & $0.66 \mathrm{~m}$ \\
\hline $\begin{array}{l}\text { Bolt size (diameter) } \\
\text { Shaft diameter }\end{array}$ & $7 \mathrm{~mm}$ \\
\hline Mixer efficiency & $50 \mathrm{~mm}$ \\
\hline
\end{tabular}

\section{MACHINE FABRICATION, AUTOMATION

$$
\text { AND TESTING }
$$

3.1 Machine fabrication

The fabrication of the compaction machine was done through production of the various components and assembly. The fabrication of the various parts was carried out in the mechanical engineering workshop at JKUAT and Multimedia University. Standard parts were purchased from local dealers. The fabrication was modular, and at each stage on completion of a module, the module was tested for functionality before final assembly. The entire machine was assembled and tested to make sure that it functions as intended.

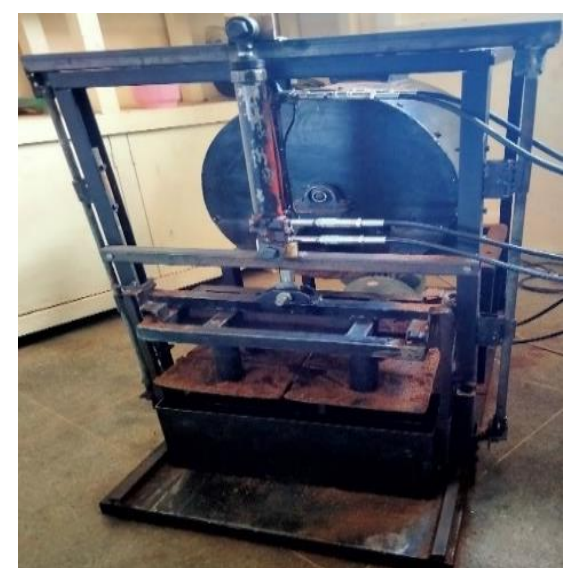

Plate 6: Fabricated machine

\section{Frame}

In machine fabrication, the frame was made of $\mathrm{U}$ - channels. The material used is mild steel. The machine frame was made in a way that it can be assembled and dis- assembled for ease of moving it from one location to another. The cylinder frame was made of mild steel sheets.

\section{The mold}

The mold box assembly consists of two sides the longitudinal side and the lateral side. These sides form the longer side has a landing or conveyor for ease of filling the mold. It was made of mild steel.

\section{Compaction plate.}

The compaction plate was made of mild steel. It is placed below the mold.

\section{The compacting chamber}

The compaction chamber was made of mild steel. Considering end fixity points where both ends are fixed, the piston dimensions were round bars.

\section{Mixing cylinder}

The mixing cylinder designed to accommodate the volume of mix needed to produce blocks per cycle using a plate of required thickness. The mixing cylinder used bolts and nuts so that the mixing shaft can be dis-mantled from the cylinder when needed. The mixing cylinder included a shaft and an electric motor.

\subsection{Hydraulic system circuit}

The hydraulic system used consisted of three hydraulic cylinders, hose pipes, hydraulic pump, hydraulic valves and hydraulic reservoir tank. It also included sliding guides to align the moving parts. The hydraulic circuits transmit and control the power from mechanical input to mechanical output by means of liquids. Power transmitted hydrostatically. High pressures make static forces dominate over dynamic forces and energy is transmitted through static pressure at low flow velocities. The hydraulic pump pushes hydraulic fluid through the system to create fluid power. This fluid passes though the valves and flows to the cylinder where hydraulic energy converts into mechanical energy. Valves help to direct flow of the liquid and receive pressure as needed. The hydraulic system circuit is as shown in fig 1 below using FluidSim Hydraulic system circuit 


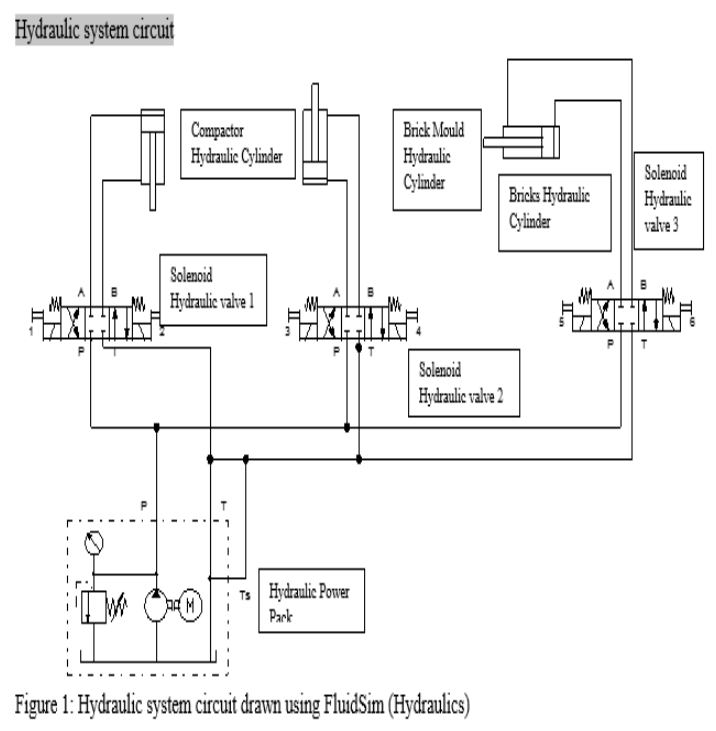

3.3 Machine control programme

The machine control programme was done using lader logic as below.



Plate 2: Machine control programme using ladder logic

\subsection{PLC Control Circiut}

The programmable control logic (PLC) is an industrial control system that continuously monitors the state of the input devices and does decisions based on a custom program to control the state of the output devices. It has the advantage of changing and replicating the operation or process while collecting and communicating vital information. There are four basic steps in the operation of PLCs, input scan, program scan, output scan, and housekeeping. Input scan detects the state of all the input devices that are connected to the PLC. The program scan executes the user created program logic. Output scan energizes or de-energizes all output devices that are connected to the PLC. Housekeeping step includes communications with programming terminals and internal diagnostics.

The control circuit used to control the operation of machine is as in plate 3 . 
Plate 3: Control circuit

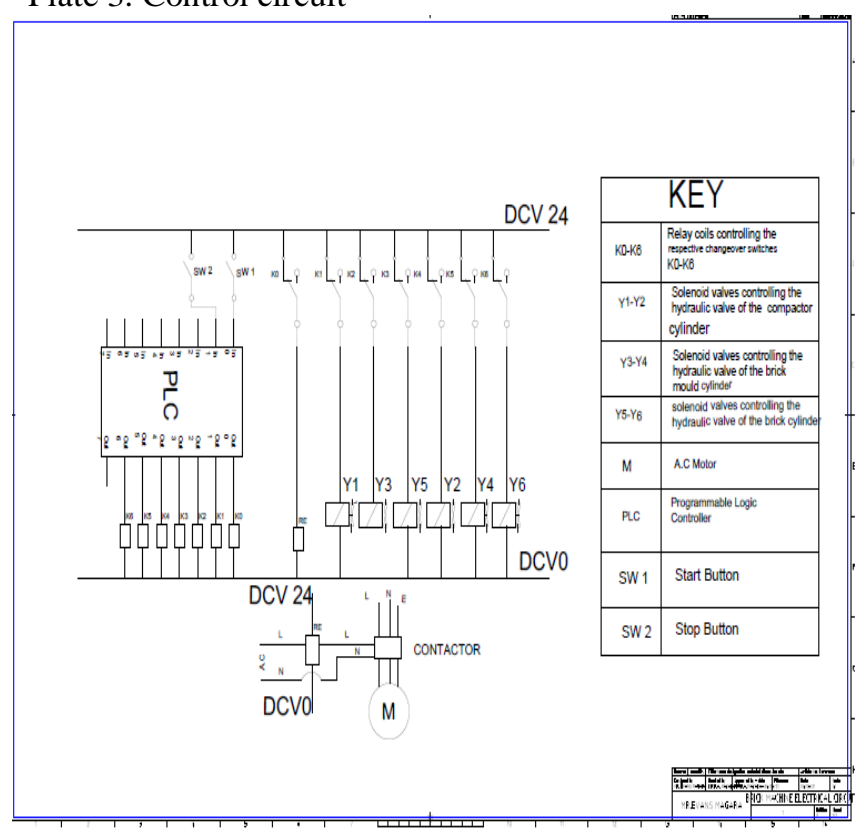

\subsection{Machine Testing}

Testing was critical as the machine was already assembled. Each component was first tested separately before the machine was tested as a whole. The hydraulic system was tested manually by means of directional- control valves to sure it works according to the design. This was done by trying to move the pistons up and down using buttons on hydraulic control system. The pressure control and the relief valves were tested to be sure that they are working well and that their performance is as required. The pressure indicator was monitored to ensure that the piston motion stops at the required pressure.

The next phase was to test the machine to ensure that it is working correctly as per the design. The test showed that the control system worked well. This indicated that the machine works as designed.

\section{CONCLUSION}

The cocopeat compaction machine was designed, fabricated and tested. This machine is the main purpose of this project. This machine has many benefits. Compacting cocopeat is the most important benefit of the machine. Compacting cocopeat reduces its volume to make it easier to transport to agricultural farms which are usually located far from the cocopeat production areas. This increases savings in transportation costs, which will include in savings in fuel cost, labour cost, cost of whole truck of un compacted cocopeat, and maintenance costs for transportation trucks. These costs savings are an indication that the cocopeat compacting machine has reached its goal. It also helps in keeping the environment clean as it prevents overfilling of coconut shells in the farms, which are breeding zones for snakes and mosquitoes. Preventing or eliminating these heaps of coconut shells makes our country look attractive and thus improving the overall image of our nation. It works without human interference, which will allow people to use it with ease. It is safe to use and portable.

\section{RECOMMENDATIONS}

The recommendations that could be done in order to reach a better solution to compacting cocopeat are either expensive or more advanced for a single product manufacture. Installing a solar panel unit, which will operate the machine using solar energy, which is a renewable energy source. This will reduce the machine running cost and make the machine more portable and for use in areas where there is no grid power.

\section{Acknowledgements}

I acknowlege the technical staff of Multimedia University for the technical assistance offered in the development of these paper. The management of Multimedia University for providing necessary equipment and materials and laboratories for all works done and the research chair, JKUAT, for their valuable guidance.

\section{REFERENCES}

1 A study on the Physical and Hydraulic Characteristics of Coco Peat Perlite Mixture as a Growing Media in Containerised Plant Production2017Sains Malaysia 975-980

2 Agriculture and Food Authority. (2019, November 15th). Retrieved https://agricultureauthority.go.ke/

3 Coconut Husk Mini-Chipper Machine.2016International Journal of Engineering Research and General Science412091-2730

4 Design and development of Waste compactor for plastic bottles , metals cans and papers2018university of Engineering college, Debrezeit, Ethiopia.

5 Design and Fabrication of Coir Pith Prequetting Machine2009World Applied Sciences Journal74552-558

6 Design and fabrication of Briquetting Machine for Solid Waste.2018International Journal of Latest Engineering Research3561-66

7 Design and Fabrication of Coco Pith Block Making Machine2017International Journal of Engineering and Advanced technilogy (IJEAT) 64

8 Design construction and performance evaluation of a cocopeat block making machine2019International Journal of Science and Technology.52202-212

9 Design Construction and testing of a Briqueting machine 2014Kwame Nkuruma University of Science and Technology - College of Engineering175 
International Journal of Engineering Applied Sciences and Technology, 2021

Vol. 6, Issue 5, ISSN No. 2455-2143, Pages 47-60

Published Online September 2021 in IJEAST (http://www.ijeast.com)

10 Design, Construction, and performance evaluation of a cocopeat block making machine2019International Journal of Science and Technology52202-212

11 Developemt of Briquette from Coir Dust and Rice Blend: An Alternative Energy Source2014International Journal of Renewable Energy Development (IJRED)32119-123

12 Development of a Coconut Dehusking for rural small scale farm holdersInternational Journal of Innovative Technology and Creative Engineering231-7

13 Development of a Light Weight Briquetting Machine for Small and Medium Scale Enterprises FUPRE2018Journal of Science and Industrial Research212579-184

14 Kenya Bureau of Statistics 2019Economic Survey

15 Kenya National Bureau of Statistics2018Economic Survey 2018 Nairobi

16 Performance Evaluation of Manually Operated Tamarind Briquetting Machine2013International Journal of Food, Agriculture and Veterinatry Sciences 3349-54

17 Production and quality testing of fuel briquettes made from pongamia and and tamarind shell2018Indian Academy of Sciences 1-7

18 Research Factors Influence on Quality of Wood Briquettes2007Journal Acta montanista ,Slovaca123223-230

19 The Mutipurpose Utilization of Coconut By Products in Agriculture : Prospects and Concerns.2017International Journal of Current Microbiology and Applied Sciences 661408-1415

20 The Effect Of Improvement On Work Facility Of Coco Bristle Process To Occupational Health And Safety.2018Indonesian Journal Of Community Engagement 